\begin{tabular}{|c|c|c|}
\hline $\begin{array}{c}\text { OPEN } \\
\text { JOURNAL } \\
\text { SYSTEMS } \\
\end{array}$ & $\begin{array}{l}\text { Available on line at Directory of Open Access Journals } \\
\text { Journal of Hyperspectral Remote Sensing v.10, n.2 (2020) 87-94 }\end{array}$ & $\begin{array}{c}\text { Journal of } \\
\text { Hyperspectral } \\
\text { Remote Sensing }\end{array}$ \\
\hline ISSN:2237-2202 & & www.ufpe.br/jhrs \\
\hline
\end{tabular}

\title{
Application of PRISMA satellite hyperspectral imagery to mineral alteration mapping at Cuprite, Nevada, USA
}

\author{
Enton Bedini*, Jiang Chen ${ }^{* *}$
}
*International Institute of Geo-information Science and Earth Observation (ITC), Enschede, The Netherlands. Geological Institute, Tirana, Albania. Email: enton_bedini@ hotmail.com. (Corresponding author).
*** Shenyang Institute of Geology and Mineral Resources, CGS, Shenyang, Liaoning, 110034, China. Email: chen07761@itc.nl

Received 11 june 2020; accepted 29 july 2020

\begin{abstract}
The PRISMA hyperspectral imaging satellite of the Italian Space Agency was launched into orbit on March 22, 2019. The PRISMA is a pushbroom sensor that records 250 hyperspectral bands in the 0.4-2.5 $\mu \mathrm{m}$ wavelength region at a spatial resolution of $30 \mathrm{~m}$. The swath of the hyperspectral imagery is $30 \mathrm{~km}$. This study evaluates the application of the PRISMA hyperspectral imagery to mineral exploration. The study area is the Cuprite in Nevada, USA. Cuprite has served as test-site for a number of airborne and spaceborne remote sensing imaging systems. The Cuprite PRISMA hyperspectral data were analyzed with the Adaptive Coherence Estimator algorithm. The analysis of the hyperspectral imagery accurately mapped the spatial distribution of alunite, kaolinite, hydrated silica, muscovite and buddingtonite. The study shows that the PRISMA hyperspectral imagery is a useful tool for mineral exploration projects in arid and semi-arid environments.

Keywords: hyperspectral, satellite, mineral exploration, PRISMA, reflectance spectroscopy.
\end{abstract}

\section{Introduction}

The PRISMA (PRecursore IperSpettrale della Missione Applicativa, Hyperspectral Precursor of the Application Mission) hyperspectral imaging satellite of the Italian Space Agency was launched into orbit on March 22, 2019 (Loizzo et al., 2019). The PRISMA hyperspectral data are recorded by a pushbroom sensor providing 250 bands in the $0.4-2.5 \mu \mathrm{m}$ wavelength region at a spatial resolution of $30 \mathrm{~m}$ (Labate et al., 2009). The swath of the imagery is $30 \mathrm{~km}$. The spectral resolution is about $12 \mathrm{~nm}$. In addition, panchromatic imagery of $5 \mathrm{~m}$ spatial resolution is simultaneously recorded as well. The sensor is equipped with an Internal Calibration Unit to support accurate radiometric and spectral calibrations (Loizzo et al., 2019; Loizzo et al., 2018; Labate et al., 2009). The PRISMA satellite hyperspectral data are useful in many applications including environmental monitoring, agriculture, forest and grassland mapping, hydrology, glaciology, natural resources etc.

The visible to short wave infrared $(0.4-2.5 \mu \mathrm{m})$ region of the electromagnetic spectrum provides mineralogic information due to electronic transitions and vibrational processes in minerals (Clark, 1999).

This wavelength region of the electromagnetic spectrum where also the PRISMA sensor records hyperspectral imagery is important for the airborne and spaceborne geological remote sensing (e.g. Vincent, 1997; Sabins, 1999; van der Meer et al., 2012; Bedini, 2017). The high-sulfidation quartz-alunite epithermal gold deposits show strong hydrothermal alteration of the wall-rock. The sulphates and clay-minerals (e.g., alunite, kaolinite, illite) that occur in the hydrothermal alteration zones of high-sulfidation epithermal gold deposits have unique spectral reflectance features in the short-wave infrared wavelength region (e.g. Clark, 1999; Clark et al., 2003).

The hydrothermal alteration system exposed at Cuprite in Nevada, USA has served as test site for airborne and spaceborne multispectral and hyperspectral imaging systems (e.g. Goetz and Srivasatava, 1985; Kruse et al., 1990; Kruse et al., 2003; Swayze et al., 2014; among many others). The purpose of this paper is to report on the use of PRISMA satellite hyperspectral imagery for the detection and mapping of mineral alteration at Cuprite, Nevada. The focus of the study are the short-wave infrared-active minerals (sulphates, clays, opal, and buddingtonite) that are important for the characterization of the surface-exposed alteration at Cuprite. The results of the study should be useful for the evaluation of the PRISMA satellite hyperspectral imagery for mineral exploration applications. 


\section{Materials and methods}

\section{Study area}

The Cuprite study area is an arid environment in southwestern Nevada, USA (Figure 1). The Cuprite has attracted the interest of exploration geologists due to well-exposed zones of hydrothermal alteration occurring in two centers on each side of U.S. Highway 5 (Figure 1, Ashley and Abrams, 1980). A recent review of the geology of Cuprite area is provided by
Swayze et al. (2014). West of Highway 95, the altered rocks consist of Cambrian meta-sedimentary rocks, Tertiary conglomerates, and intrusive rocks composed of quartz latites and syeno-monzonites. East of the Highway 95, the altered rocks consist of Tertiary rhyolitic ashflow, conglomerate, and basalt (Swayze et al., 2014). The eastern and western rock alteration centers are separated by Quaternary deposits.

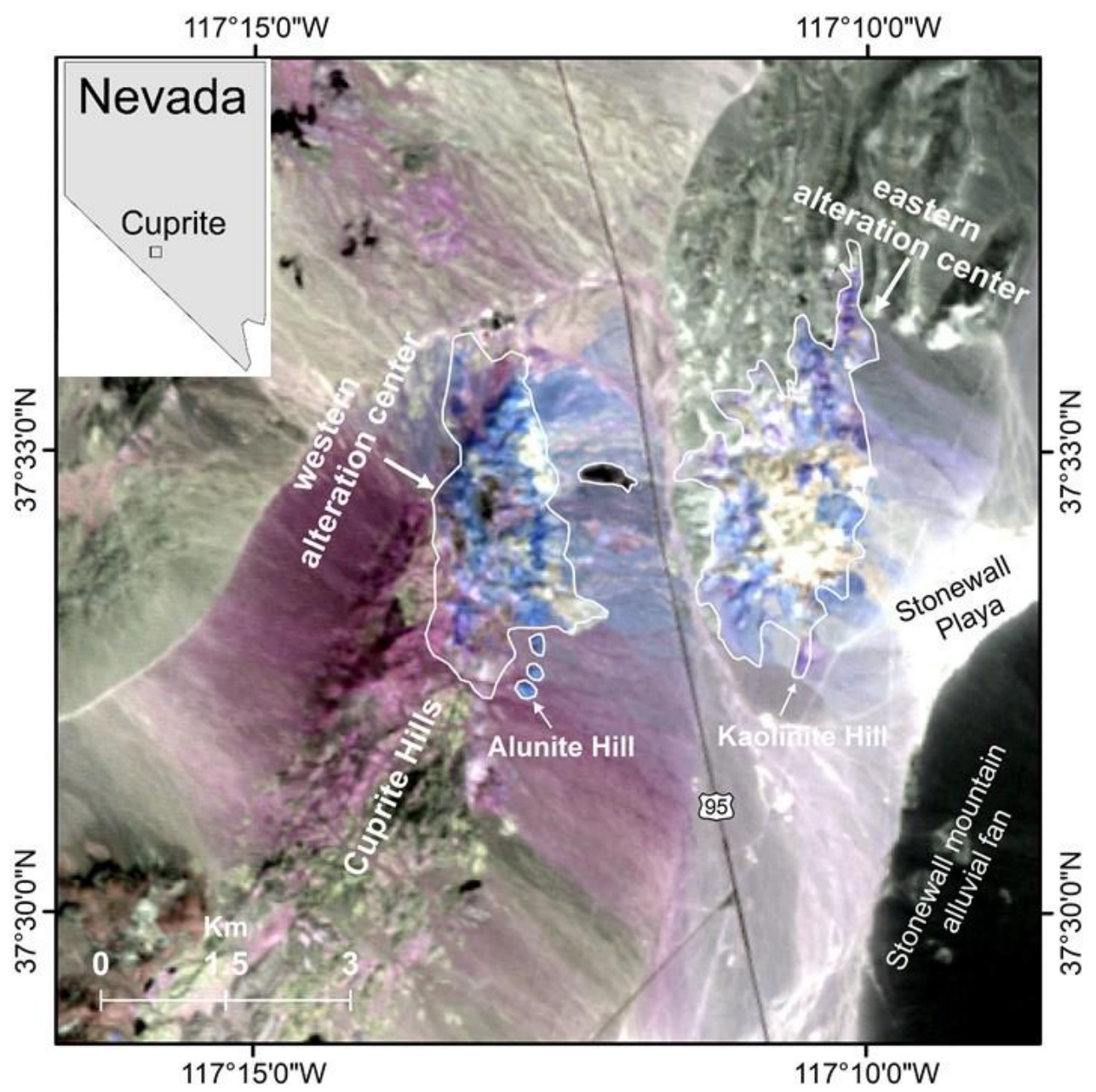

Figure 1 - The Cuprite study area in Nevada, USA. The approximate spatial extent of the hydrothermal alteration centers at Cuprite (modified from Ashley and Abrams, 1980) is also shown on the image. The background is an RGB color composite of the PRISMA hyperspectral channels $(2.167 \mu \mathrm{m}=$ red, $2.206 \mu \mathrm{m}=$ green, $2.267 \mu \mathrm{m}=$ blue $)$.

Ashley and Abrams (1980) distinguished silicified, opalized, and argillized altered rocks units (Figure 2). The highest degree of alteration occurs in the silicified rocks. The most widespread alteration zone is the opalized. The silicified rocks consist of quartz, chalcedony, and minor alunite and kaolinite. In the opalized alteration zone, in addition to opal, variable amounts of alunite and kaolinite are present. Argillized areas, located within the opalized rock units or at the edge of the altered areas, contain kaolinite, illite, opal (Ashley and Abrams, 1980). 


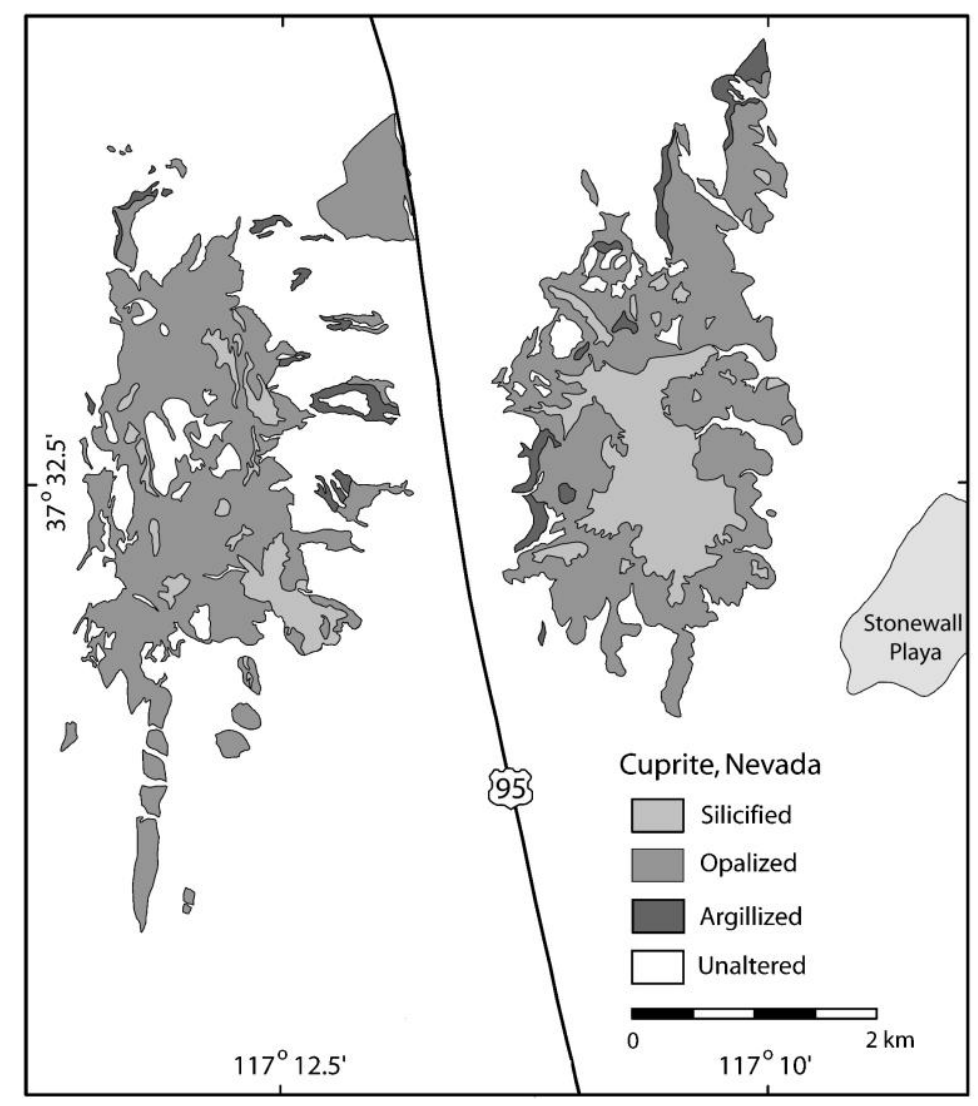

Figure 2 - Alteration map of the Cuprite area based on field mapping and airborne multispectral remote sensing (modified from Ashley and Abrams, 1980).

\section{Spectral reflectance properties}

The surface-exposed alteration zones at Cuprite contain a number of infrared-active minerals (e.g., Ashley and Abrams, 1980; Swayze et al., 2014). Especially alunite, kaolinite, opal, chalcedony, illite/muscovite, and buddingtonite are useful to characterize the surface mineralogy of the alteration system at Cuprite (e.g., Swayze et al., 2014). These minerals have absorption features in the short-wave infrared wavelength region (Figure 3 and 4).

Alunite, a sulphate mineral, is characteristic for the advanced argillic alteration zone of high-sulfidation epithermal gold deposits (e.g., Bedini et al., 2009; Pirajno, 2009). The alunite infrared reflectance spectrum in the 2-2.5 $\mu \mathrm{m}$ wavelength region displays characteristic Al-OH alunite absorption features (Figure 3; Hunt and Ashley, 1979; Bishop and Murad, 2005). Kaolinite, a clay mineral, occurs together with alunite in the advanced argillic alteration zone, and is especially characteristic for the argillic alteration zone of epithermal gold deposits (e.g., Bedini et al., 2009; Pirajno, 2009). The reflectance spectrum of kaolinite displays a diagnostic doublet $\mathrm{Al}-\mathrm{OH}$ absorption feature occurring at 2.16-2.2 $\mu \mathrm{m}$ (Figure 3 ).
In the alteration zones of high-sulfidation epithermal quartz-alunite gold deposits illite and muscovite occur as spectral dominant classes in the outer parts of the argillic alteration or in the propylitic alteration zone. Characteristic for muscovite (and illite) is the presence of an $\mathrm{Al}-\mathrm{OH}$ absorption feature centered at around $2.2 \mu \mathrm{m}$ (Figure 3; Hunt and Ashley, 1979). A particular feature of the surface alteration at Cuprite is the occurrence of a large area in the eastern alteration center consisting of chalcedony and opal. The reflectance spectra of opal and chalcedony display Si-OH (silanol) absorption features (Figure 4; Swayze et al., 2014).

A previously undetected occurrence of buddingtonite (an $\mathrm{NH}_{4}$-feldspar mineral) was discovered with imaging spectroscopy at Cuprite (Goetz and Strivastava, 1985). The ammonia in buddingtonite (and in other $\mathrm{NH}_{4}$-bearing minerals) has a distinct $\mathrm{N}-\mathrm{H}$ combination absorption at around 2.12 $\mu \mathrm{m}$ (Figure 3; Swayze et al., 2014). Buddingtonite can be formed by alteration of primary feldspar when hydrothermal fluids incorporate ammonium from buried plant matter (Hallam and Eugster, 1976). 


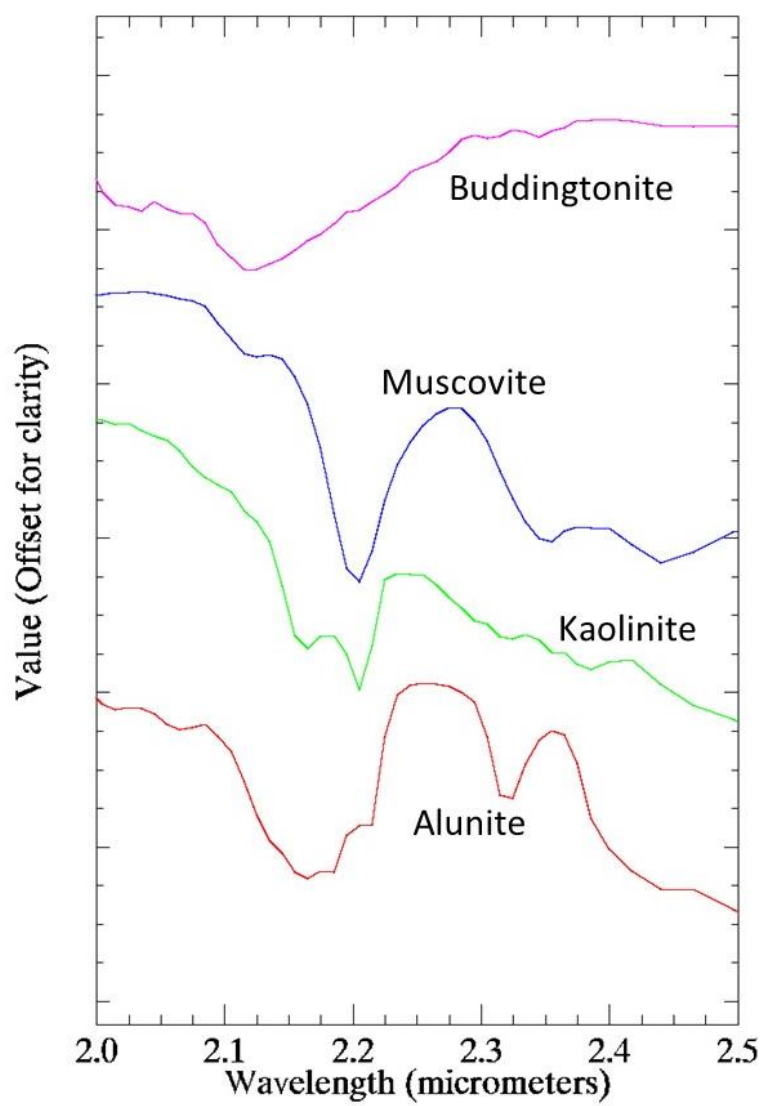

Figure 3 - Reflectance spectra from the USGS spectral library of alunite, kaolinite, muscovite and buddingtonite (Clark et al., 2007).

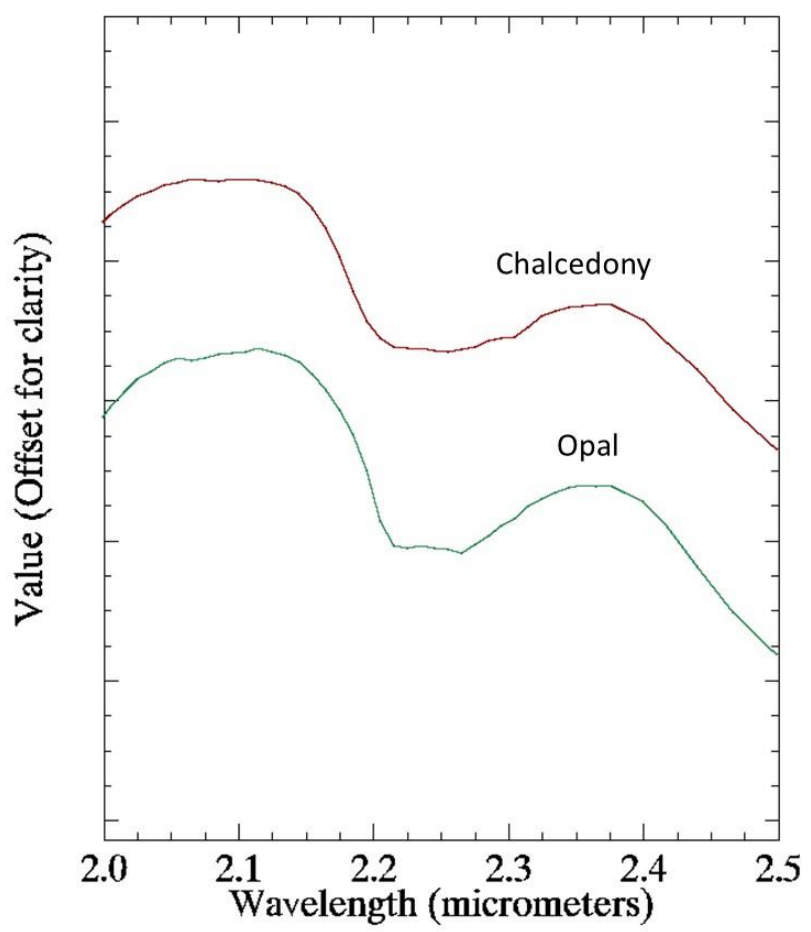

Figure 4 - Reflectance spectra from the USGS spectral library of chalcedony and opal (Clark et al., 2007). 
Analysis of Cuprite PRISMA hyperspectral imagery

The PRISMA hyperspectral imagery was recorded on April 13, 2020. The analysis of PRISMA hyperspectral imagery was focused in the short-wave infrared wavelength region where diagnostic absorption features of the main alteration minerals occur. The data were processed using the Adaptive Coherence Estimator (ACE), a partial unmixing algorithm (e.g., Manolakis et al., 2016). The Adaptive Coherence Estimator is described as the squared matched filter normalized by terms proportional to the magnitude of the target in the matched filter space and the magnitude of the reference spectrum in the matched filter space (e.g., Schott, 2007).

The reference spectra were derived from the PRISMA hyperspectral imagery using the "hourglass" processing scheme (e.g., Kruse et al., 2006; Boardman and Kruse, 2011). This processing scheme is based on convex and affine geometry to select the purest pixel spectra in an image by using the Pixel Purity Index (PPI) method (e.g., Boardman et al., 1995). The "hourglass" processing scheme consists of noise suppression and dimensionality reduction using the Minimum Noise Fraction (MNF) transformation (Green et al., 1988) determination of endmembers (or "reference spectra") using the Pixel Purity Index method (Boardman et al., 1995), extraction of the reference spectra using n-dimensional scatter plotting (Boardman et al., 1995), identification of the reference spectra using spectral library comparisons (e.g., Kruse et al. 2006). The reference spectra of alunite, kaolinite, illite/muscovite, hydrated silica (opal, chalcedony) and buddingtonite were derived from the PRISMA shortwave infrared bands $(2-2.5 \mu \mathrm{m})$. These image-derived reference spectra were used as input to the ACE algorithm.

\section{Results and discussion}

The results of the ACE algorithm for the alteration minerals at Cuprite, Nevada are shown in Figure 5. A color composite of alunite, kaolinite and opal is shown in Figure 6. Alunite is the most abundant spectral class in the alteration zones at Cuprite. The mineral alunite is an indicator of the advanced argillic alteration zone of the epithermal high-sulfidation gold deposits. However, it can also occur as a supergene secondary formation. The spectral class kaolinite is less widespread than alunite. Both the so-called Alunite Hill and Kaolinite Hill are accurately mapped (Figure 5 , 6) from the analysis of the PRISMA satellite hyperspectral data. The results for these minerals compare well also with results from airborne hyperspectral data analysis and field mapping (e.g., Swayze et al., 2014). The results for illite/muscovite show that these minerals occur in small zones within the western alteration center (Figure 5).

A characteristic at Cuprite is the occurrence of a large zone in the eastern alteration center predominated from the spectral response of hydrated silica (opal and chalcedony). The hydrated silica zone (e.g., Swayze et al., 2014) despite its relatively nonunique spectral features, is accurately detected from the PRISMA hyperspectral data analysis at the eastern alteration center of Cuprite. The PRISMA hyperspectral data have also accurately detected the occurrence of the zone dominated from the spectral reflectance of buddingtonite, an $\mathrm{NH}_{4}$-feldspar. Buddingtonite, a phase not normally associated with the advanced argillic alteration, may be remnant from an earlier stage of adularia-sericite-type alteration (Swayze et al., 2014). 
$117^{\circ} 15^{\prime} \mathrm{O} \mathrm{W}$

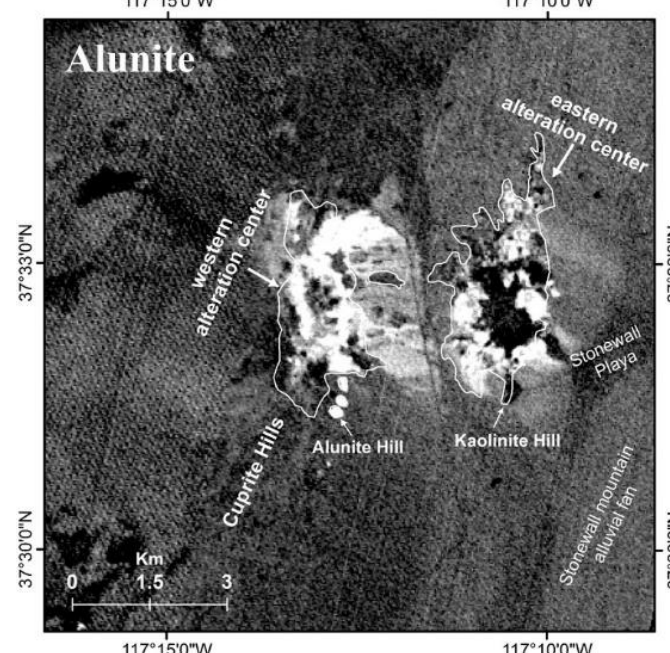

$117^{\circ} 15^{\prime} 0^{\prime \prime W}$

$117^{\circ} 15^{\circ} \mathrm{O}^{\mathrm{N} W}$

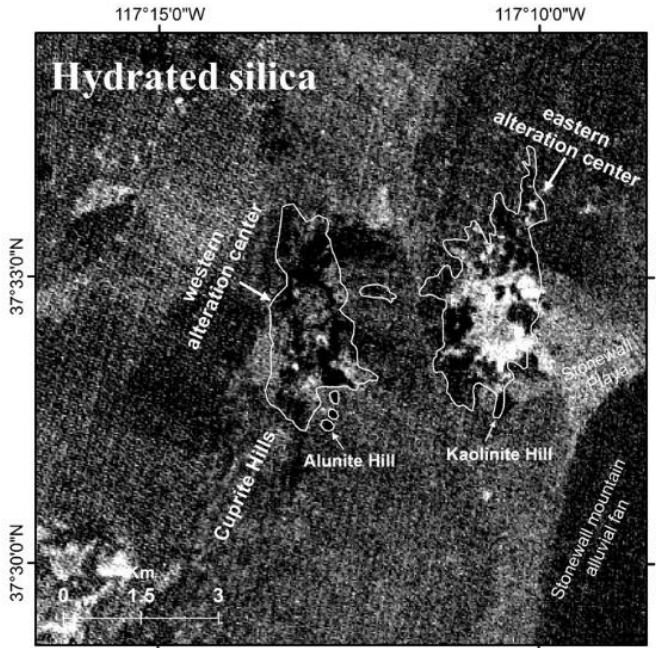

$117^{\circ} 15^{\prime} 0^{\prime \prime} \mathrm{W}$

$117^{\circ} 15^{\prime} \mathrm{O}^{\circ} \mathrm{W}$

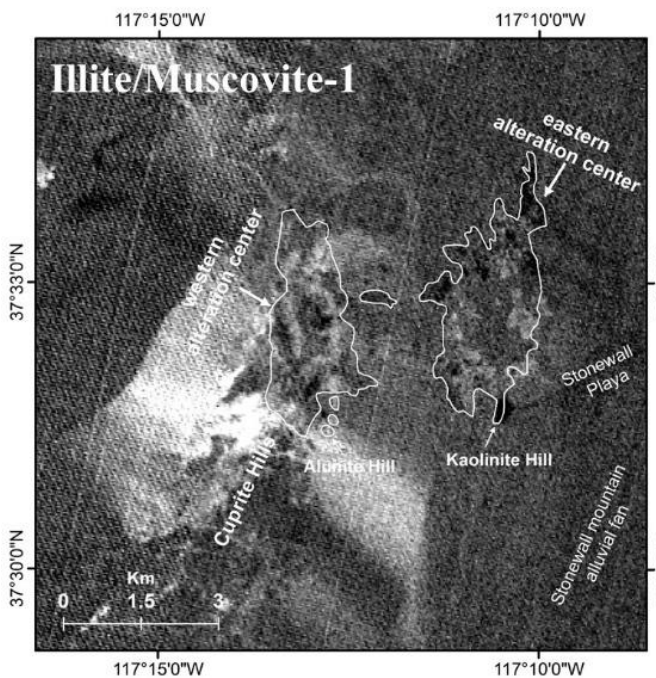

$117^{\circ} 15^{\prime} \mathrm{O}^{\prime \prime} \mathrm{W}$

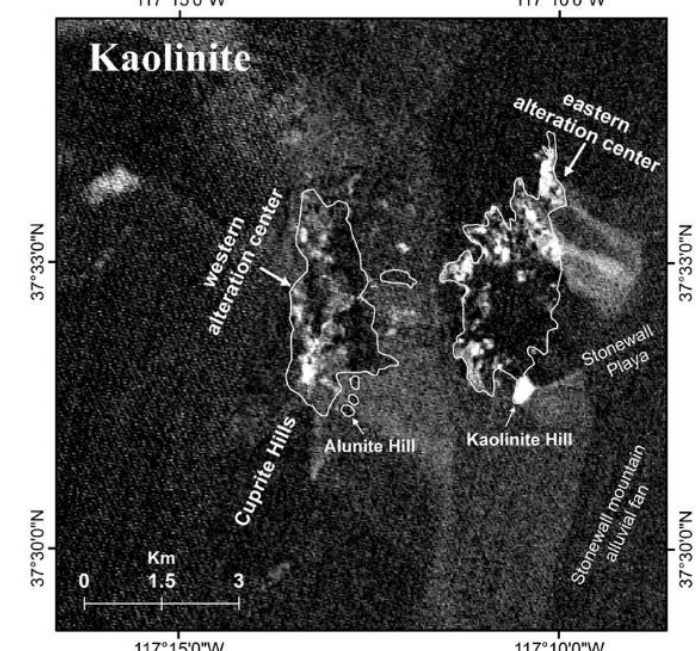

$117^{\circ} 15^{\prime} 0^{\prime \prime} \mathrm{W}$

$117^{\circ} 10^{\circ} 0^{\prime \prime} \mathrm{W}$

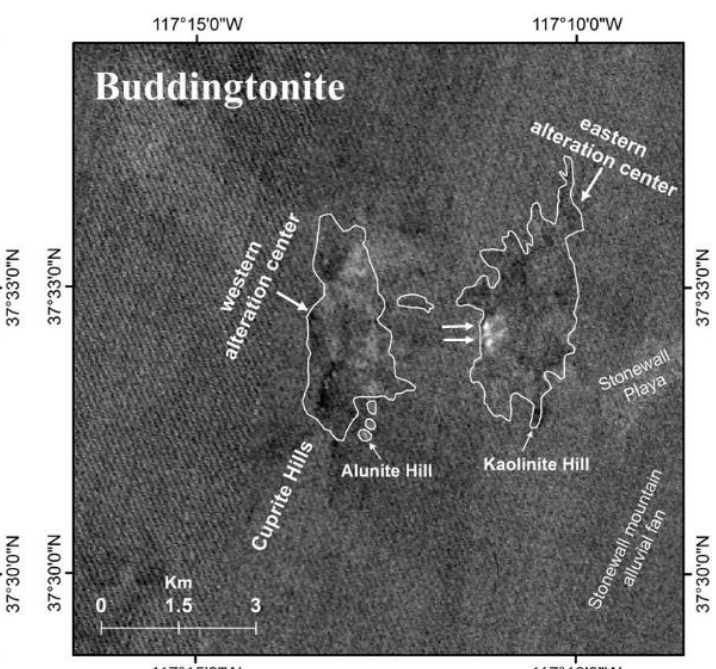

$117^{\circ} 15^{\prime} 0^{\prime \prime W}$

$117^{\circ} 10^{\circ} 0^{\prime \prime} \mathrm{W}$

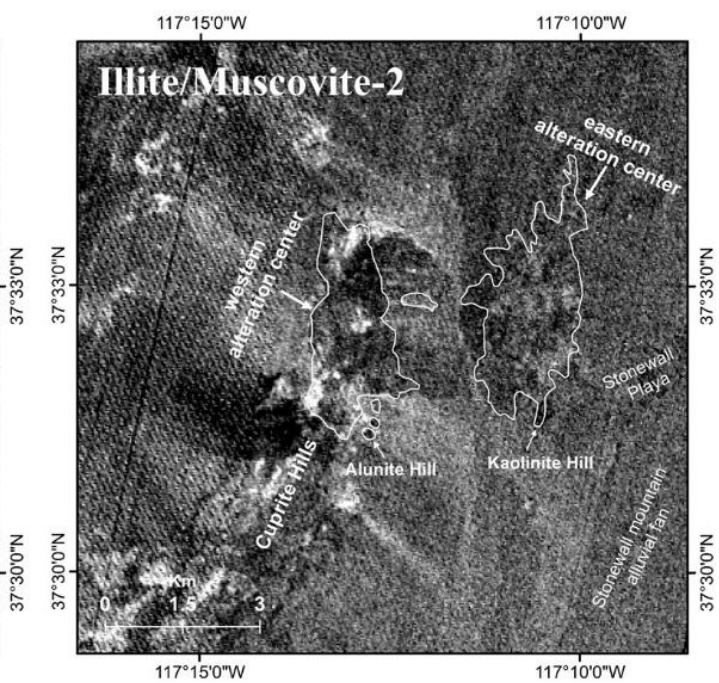

Figure 5 - Results of Adaptive Coherence Estimator (ACE) analysis of Cuprite PRISMA satellite hyperspectral data. Brighter levels of grey show higher abundances. The spatial extent of altered rocks (from Ashley and Abrams, 1980) is plotted onto the images for reference with Figure 1. 


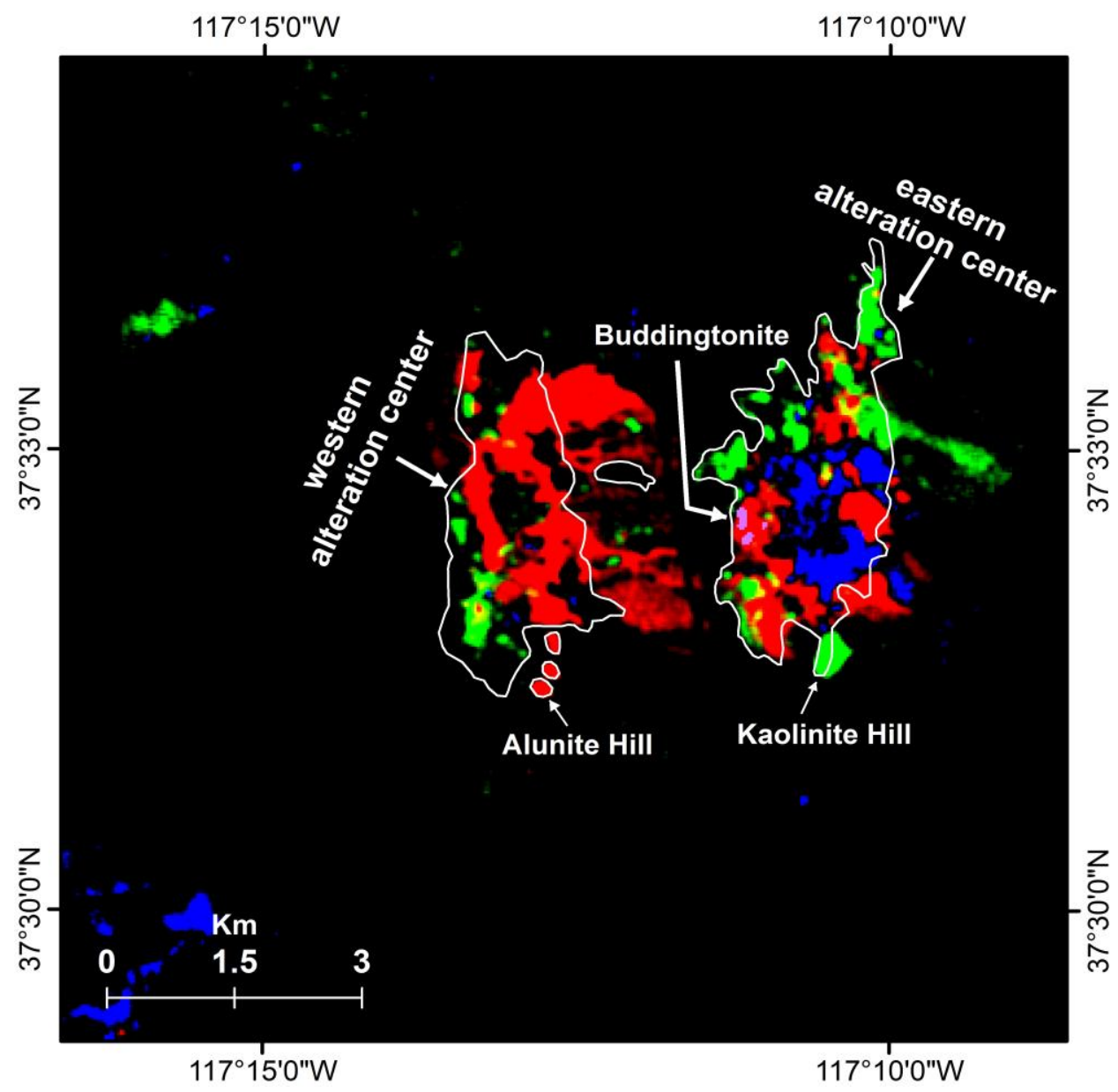

Figure 6 - Color composite of the results for alunite (red), kaolinite (green), hydrated silica (blue). The mapping results for the mineral buddingtonite (shown by violet color pixels at the eastern alteration center) are plotted onto the color composite as well.

\section{Conclusions}

The PRISMA satellite hyperspectral imagery was evaluated for mineral detection and mapping at the alteration system of Cuprite, Nevada. The results show that PRISMA hyperspectral data can accurately detect alteration minerals such as alunite, kaolinite, illite/muscovite. In addition, the hydrated silica zone at Cuprite (e.g., Ashley and Abrams, 1980; Swayze et al., 2014) was correctly mapped using the PRISMA satellite hyperspectral data. The detection of the buddingtonite spectral class that is confined to a relatively small area at Cuprite, and that has a particular reflectance spectrum is an indicator that the $30 \mathrm{~m}$ spatial resolution spaceborne PRISMA hyperspectral data can be successfully used for the detection of rare targets. The PRISMA satellite of the Italian Space Agency represents an advancement in the spaceborne hyperspectral remote sensing technology. The PRISMA hyperspectral data are also valuable for mineral exploration studies.

\section{Acknowledgment}

The study was carried out using PRISMA Products, (C) of the Italian Space Agency (ASI), delivered under an ASI License to use. The Italian Space Agency is thanked for providing the PRISMA hyperspectral data.

\section{References}

Ashley, R.P., Abrams, M.J., 1980. Alteration mapping using multispectral images, Cuprite mining district, Esmeralda County, Nevada: U.S. Geological Survey Open File Report 80-367.

Bedini, E., 2017. The use of hyperspectral remote sensing for mineral exploration: A review. Journal of Hyperspectral Remote Sensing 7, 189-211.

Bedini, E., van der Meer, F., van Ruitenbeek, F., 2009. Use of HyMap imaging spectrometer data to map mineralogy in the Rodalquilar caldera, southeast 
Spain. International Journal of Remote Sensing 30, 327-348.

Bishop, J.L., Murad, E., 2005. The visible and infrared spectral properties of jarosite and alunite. American Mineralogist 90, 1100-1107.

Boardman, J.W., Kruse, F.A., 2011. Analysis of imaging spectrometer data using $\mathrm{N}$-dimensional geometry and a mixture-tuned matched filtering approach. IEEE Transactions on Geoscience and Remote Sensing 49, 4138-4152.

Boardman, J.W., Kruse F.A., Green R.O., 1995. Mapping target signatures via partial unmixing of AVIRIS data, in: Fifth JPL Airborne Earth Science Workshop. Jet Propulsion Laboratory Publ., Summaries.

Clark, R.N., Swayze, G.A., Wise, R., Livo, E., Hoefen, T., Kokaly, R., Sutley, S.J., 2007. USGS digital spectral library splib06a: U.S. Geological Survey, Digital Data Series 231. Available: http://speclab.cr.usgs.gov/spectral.lib06.

Clark R.N., Swayze G.A., Livo, K.E, Kokaly, R.F, Sutley, S.J, Dalton, J.B, McDougal, R.R, Gent, C.A., 2003. Imaging spectroscopy: Earth and planetary remote sensing with the USGS Tetracorder and expert systems. Journal Geophysical Research-Planets 108, 44.

Clark, R.N., 1999. Spectroscopy of rocks and minerals, and principles of spectroscopy, in: Rencz, A.N. (ed.), Remote Sensing for the Earth Sciences. v. 3. John Wiley, New York, pp. 3-58.

Goetz, A.F.H., Srivastava, V., 1985. Mineralogical mapping in the Cuprite mining district, Nevada. Proceedings of the Airborne Imaging Spectrometer Data Analysis Workshop. JPL Publication, Pasadena.

Green, A.A., Berman, M., Switzer, B., Craig, M.D., 1988. A transformation for ordering multispectral data in terms of image quality with implications for noise removal, IEEE Trans. Geosci. Remote Sensing 26, 65-74.

Hallam, M., Eugster, H.P., 1976. Ammonium silicate stability relations. Contributions to Mineral Petrology 57, 227-244.

Hunt, G.R. and Ashley, R.P., 1979. Spectra of altered rocks in the visible and near infrared. Economic Geology 74, 1613-1629.

Kruse, F.A., Perry, S.L., Caballero, A., 2006. Districtlevel mineral survey using airborne hyperspectral data, Los Menucos, Argentina. Annals of Geophysics 49, 83-92.

Kruse, F.A, Boardman, J.W., Huntington, J.F., 2003. Comparison of airborne hyperspectral data and EO-
1 Hyperion for mineral mapping. IEEE Transactions on Geoscience and Remote Sensing 41, 1388-1400.

Kruse, F.A., Kierein-Young, K.S., Boardman, J.W., 1990. Mineral mapping at Cuprite, Nevada with a 63 channel imaging spectrometer. Photogrammetric Engineering and Remote Sensing 56, 83-92.

Labate, D., Ceccherini, M., Cisbani, A., De Cosmo, V., Galeazzi, C., Giunti, L., Melozzi, M., Pieraccini, S., Stagi, M., 2009. The PRISMA payload optomechanical design, a high performance instrument for a new hyperspectral mission. Acta Astronautica 65, 1429-1436.

Loizzo, R., Daraio, M., Guarini, R., Longo, F., Lorusso, R., Dini, L., Lopinto, E., 2019. Prisma Mission Status and Perspective. IEEE International Geoscience and Remote Sensing Symposium, pp. 4503-4506.

Loizzo, R., Guarini, R., Longo, F., Scopa, T., Formaro, R., Facchinetti, C., Varacalli, G., 2018. PRISMA: The Italian hyperspectral mission. IEEE International Geoscience and Remote Sensing Symposium, pp. 175-178.

Manolakis, D., Lockwood, R., Cooley, T., 2016. Hyperspectral Imaging Remote Sensing: Physics, Sensors, and Algorithms. Cambridge University Press, Cambridge.

Pirajno, F., 2009. Hydrothermal Processes and Mineral Systems. Springer/Geological Survey of Western Australia, Dordrecht.

Sabins, F.F., 1999. Remote sensing for mineral exploration. Ore Geology Reviews 14, 157-183.

Schott, J.R., 2007. Remote Sensing. The Image Chain Approach. 2. ed. Oxford University Press, New York.

Swayze, G.A., Clark, R.N., Goetz, A.F.H., Livo, K.E., Breit, G.N., Kruse, F.A., Sutley, S.J., Snee, L.W., Lowers, H.A., Post, J.L., 2014. Mapping Advanced Argillic Alteration at Cuprite, Nevada, Using Imaging Spectroscopy. Economic Geology 109, 1179-1221.

van der Meer, F.D., van der Werff, H.M., van Ruitenbeek, F.J., Hecker, C.A., Bakker, W.H., Noomen, M.F., Van Der Meijde, M., Carranza, E.J.M., De Smeth, J.B., Woldai, T., 2012. Multi-and hyperspectral geologic remote sensing: A review. International Journal of Applied Earth Observation and Geoinformation 14, 112-128.

Vincent, R.K., 1997. Fundamentals of Geological and Environmental Remote Sensing. Prentice Hall, New York. 